\title{
Interview transcription: conceptual issues, practical guidelines, and challenges
}

Transcrever entrevistas: questôes conceptuais, orientaçóes práticas e desafios Transcripción de entrevistas: cuestiones conceptuales, orientaciones prácticas y desafíos

Vanessa Azevedo*; Margarida Carvalho**; Flávia Fernandes-Costa***; Soraia Mesquita****; Joana Soares ${ }^{* * * * *}$; Filipa Teixeira******; Ângela Maia*******

\begin{abstract}
Background: Interviews are a common practice for gathering information in scientific studies. Although there is an extensive work about how to conduct and analyze an interview, transcription has usually remained a minor issue. Transcribing is the transformation of oral speech into a written and meaningful text that includes relevant information from the interview and that can be analyzed.

Objectives: This article addresses and discusses the main conceptual and practical issues, as well as the main challenges involved in interview transcription, using an integrative approach.

Main topics under analysis: What is the definition of transcription? Which types of transcripts exist? What content must be transcribed? How should an interview be transcribed? What special measures should be taken during a transcription? What are the main difficulties?

Conclusion: Given the lack of universal protocols or rules for transcription, researchers should state their practices and decisions, which may influence data analysis.
\end{abstract}

Keywords: methodology; qualitative research; interviews as topic; nonverbal communication; verbal behavior

\section{Resumo}

Enquadramento: A recolha de informação através de entrevistas é uma estratégia de investigação comum, existindo vasta literatura sobre a realização e a análise das mesmas. Contrariamente, a transcrição tem sido um tema secundarizado, embora não irrelevante. Transcrever consiste na transformação de um discurso oral num texto escrito com significado, que possa ser analisado e que contenha as informaçóes relevantes da entrevista.

Objetivos: Abordam-se e discutem-se as questôes conceptuais, pragmáticas e desafios inerentes à transcrição de entrevistas, numa perspetiva integradora.

Principais tópicos em análise: $\mathrm{O}$ que se entende por transcrever? Que tipos de transcriçốes existem? O que é que se transcreve e como é que transcreve uma entrevista? Que cuidados devem ser salvaguardados quando transcrevermos? Quais são as principais dificuldades de se transcrever?

Conclusáo: Reconhecendo a inexistência de protocolos ou regras universais para transcrever, importa que os investigadores explicitem as suas práticas e decisōes, as quais poderão influenciar a análise de dados.

Palavras-chave: metodologia; pesquisa qualitativa; entrevistas como assunto; comunicaçáo não verbal; comportamento verbal

*MSc., Doctoral Student, University of Minho, 4710-057, Braga, Portugal [vazevedo@psi.uminho. pt]. Contribution to the article: content synthesis and organization and elaboration of a preliminary version of the manuscript, approval of the final version. Address for correspondence: Escola de Psicologia, Campus de Gualtar, Universidade do Minho, 4710-057 Braga, Portugal.

**MSc., Psychologist, School of Psychology, University of Minho, 4710-057, Braga, Portugal [margarida.mt.carvalho@gmail.com].Contribution to the article: content sunthesis and organization and elaboration of a preliminary version of the manuscript, approval of the final version.

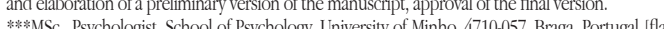
(f) viacosta_1989@hotmail.com]. Contribution to the article: content synthesis and organization and elaboration of a preliminary version of the manuscript, approval of the final version. ****12th grade, Psychology student, School of Psychology, University of Minho, 4710-057, Braga, Portugal [a74599@alunos.uminho.pt].Contribution to the article: content synthesis and organization and elaboration of a preliminary version of the manuscript, approval of the final version. ******12th grade, Psychology student, School of Psychology, University of Minho, 4710-057, Brag Portugal [a73573@alunos.uminho.pt]. Contribution to the article: content synthesis and organization and formulation of a preliminary version of the manuscript, approval of the final version. zation an a 1710 05. D., Psychologist, Research Grant Holder, School of Psychology, University of Minho, 4710-057, Braga, Portugal [filipa.v.teixeira@gmail.com]. Contribution to the article: discussion and review of the preliminary version of the manuscript, approval of the final version. ********** Ph.D., Assistant Professor, School of Psychology, University of Minho, 4710-057, Braga Portugal [angelam@psi.uminho.pt]. Contribution to the article: discussion and review of the preliminary version of the manuscript, approval of the final version.

\section{Resumen}

Marco contextual: La recogida de información a través de entrevistas es una estrategia de investigación común, y existe una vasta literatura sobre la realización y el análisis de las mismas. Por el contrario, la transcripción ha sido hasta ahora un tema secundario, aunque no irrelevante. Transcribir consiste en transformar un discurso oral en un texto escrito con significado, que pueda ser analizado y que contenga las informaciones relevantes de la entrevista.

Objetivos: Se abordan y se discuten las cuestiones conceptuales, pragmáticas y desafíos inherentes a la transcripción de entrevistas, en una perspectiva integradora.

Principales temas de análisis: Qué se entiende por transcribir? Qué tipos de transcripciones existen? Qué se transcribe y cómo transcribe una entrevista? Qué cuidados deben tenerse al transcribir? Cuáles son las principales dificultades de transcribir?

Conclusión: Puesto que reconocemos que no existen protocolos o reglas universales para transcribir, es importante que los investigadores expliciten las prácticas y decisiones que pueden influir en el análisis de datos.

Palabras clave: metodología; investigación cualitativa; entrevistas como asunto; comunicación no verbal; conducta verbal 


\section{Introduction}

The attempt to further explore the how and the whys of a given phenomenon requires providing a framework for a qualitative research. Qualitative approaches focus on the study of the meanings attributed by individuals to certain life experiences, thus making use of a type of knowledge that often cannot be quantitatively measured or that becomes insufficient when reduced to variable operationalization (Creswell, 2013). Qualitative research asserts itself in the complete and complex description and interpretation of subjective meanings and processes attributed to everyday experiences and practices, in a logic of discovery, focusing on the actors/subjects' perspectives and life contexts, that is, studying and interpreting the phenomena in their natural environment (Creswell, 2013; Silverman, 2013).

The use of qualitative methodologies is increasingly necessary in health sciences, not only as a way to achieve an in-depth understanding of thecoreofhumanexperience and the meanings attributed by individuals to their health and disease experiences, but also as a way to promote the humanization of the health-illness process, enhance evidencebased practice, and facilitate change at personal and governmental levels (Taylor \& Francis, 2013). The interest in qualitative methodologies is evident by the increasing number of qualitative studies published in the Journal of Nursing Referência: from 10 studies between 2010 and 2012 to 24 studies between 2013 and 2016.

In qualitative studies, knowledge can be acquired by using different types of materials, such as photos, texts, field observation, among others. However, interviews are the most widely used method for the comprehensive and wide-ranging collection of meanings attributed to phenomena (Ritchie, Lewis, Nicholls, \& Ormston, 2014). Therefore, a significant number of researchers in the health area have probably already transcribed an interview or worked with transcripts, which is why the main topic of this article is not unfamiliar, especially from an experiential point of view.

Bazeley (2013) emphasizes that transcription is an important research task and that, for this reason, it should not be regarded as a mere technical detail between the interview and data analysis, as it seems to be treated in most cases. More specifically, in the qualitative studies published in the Journal of Nursing Referência, only five of them have more detailed information about the transcription step (e.g., Camarneiro, Maciel, \& Silveira, 2015). This pattern can also be found at the international context (e.g., Anna Nery School Journal of Nursing). This scenario reflects the trend in the literature about transcripts, which is significantly disproportionate and dispersed when compared to the other steps. Even if it seems easy to answer questions, such as What is meant by transcribing? How do we transcribe? Which measures should be taken? What are the challenges?, the answers are unlikely to be consensual and will certainly be shaped by individual learning experiences. Consequently, it is understandable that the same interview can be transcribed in different ways by different people or even by the same person at different times, or due to different goals. Taking into account that group work and research is increasing and that the interviewer and the transcriber can be different people or even that there may be more than one transcriber, it becomes imperative to convert idiosyncratic experiences into a set of shared principles and practices.

Given the complexities inherent to transcription (e.g., Mergenthaler \& Stinson, 1992) and the scarce literature on the topic, it is important to emphasize this intermediate step, exploring in more depth the multiple tasks and continuous decisions made not only at the conceptual but also pragmatic level. Therefore, this article aims to identify, analyze, and discuss the main conceptual issues, practical guidelines, and challenges inherent to transcription, in order to understand the entire process. Given the pragmatic nature of the contents addressed, whenever relevant, they will be illustrated using a practical example from the process of transcribing verbatim and in full 12 interviews, which were conducted as part of a study carried out in the northern region of 
the country on nurses' beliefs, attitudes, and practices towards obesity and obese people in primary health care.

\section{Development}

\section{Conceptual issues}

\section{Types of Interview}

According to the adaptation of Halcomb and Davidson (2006) based on the typology of Tashakkori and Teddlie (2003), interviews can be located on a continuum that ranges from a purely quantitatively approach to a purely qualitative approach, varying in terms of structure, flexibility, and interviewer/ interviewee interaction pattern.

Regardless of the type of interview, audio recording is a current practice since it has many advantages for both the interviewer and the interviewee (Halcomb \& Davidson, 2006; Stuckey, 2014). Subsequently, the interviews of a more qualitative nature are transcribed before being analyzed with the purpose of minimizing the limitations associated with the mere intuition and recall of information and the individual biases (e.g., prejudices; Naz, n.d.). Furthermore, according to this author, transcription allows the repeated and detailed observation of the course and content of the interview, the sharing of this information with others, and reuse or reexamination of the data in other projects or according to other objectives.

\section{Definitions of transcription}

According to Halcomb and Davidson (2006, p. 38), transcription is the process of "reproducing spoken words, such as those from an audiotaped interview, into written text"; however, since it is not restricted to the simple act of listening and writing, there are more complex definitions. For example, some authors consider that "representing audible talk as written words requires reduction, interpretation and representation to make the written text readable and meaningful" (Bailey, 2008, p. 127); in this way, "transcripts are not therefore neutral records of events, but reflect researchers' interpretations of data" (Bailey, 2008, p. 129). In summary, Davidson (2009, p. 37) argues that "transcription is a process that is theoretical, selective, interpretive, and representational". Thus, it seems reasonable to acknowledge that transcribing is far from being an objective, impersonal, and mechanized task. Instead, it consists of the apprehension of what is said and how it is said in order to understand the meanings (Bailey, 2008; Stuckey, 2014).

\section{Types of transcripts: naturalized versus denaturalized}

According to some authors (Bucholtz, 2000; Oliver, Serovich, \& Mason, 2005), interview transcription is represented in a continuum with two poles, which Bucholtz (2000) has termed naturalized versus denaturalized (it should be noted that the literature may contain verbatim or integral transcription (Schegloff, 1997) versus selective transcription as synonyms), that correspond to different perspectives on the representation of language.

The naturalized transcription corresponds to the thorough transcription of what is said and how it is said, and advocates the preservation of the different elements of the interview other than the verbal content, such as non-verbal language, contextual aspects, and the interaction between interviewer and interviewee (or third parties involved; Oliver et al., 2005). On the other hand, according to these authors, denaturalized transcription prioritizes the verbal speech and focuses on the omission of idiosyncratic speech elements, such as stutters, pauses, involuntary vocalizations, and non-verbal language, thus presenting itself as a more polished and selective transcription.

\section{Practical guidelines}

The process of transforming oral speech into written words is associated with a diverse set of challenges, which can be overcome with a careful and meticulous planning about how to proceed (Lapadat, 2000). Considering that the practical guidelines refer to different aspects of the transcription process, we decided to organize them into steps. After reviewing the suggestions of other authors (e.g., Halcomb \& Davidson, 2006; McLellan, MacQueen, \& Neidig, 2003), we pro- 
pose a 6-step procedure: Prepare, know, write, edit, review, and finish, which will be described below (along with examples shown in Table 1).

Step 1. Prepare

In an initial phase, it is essential to ensure a set of basic measures to guarantee that there will be setbacks along the way. Therefore, it is essential to: Make backup copies of the recordings and keep the original recordings on different storage devices; create an identification system that will allow associating the recording file with the transcription document (Table 1); and establish the location where the material for the transcription will be stored, as well as the resulting transcripts. Nowadays, with the dispersion of material throughout multiple mobile devices (e.g., flash drives) and online storage (e.g., clouds), it is important to pay particular attention to information sharing and ensuring that no external person has access to the contents. It is also essential to gather the required materials for the transcription, and, obviously, have access to the recordings and to a device for listening to them. When transcribing without technology, only paper and pen/pencil are necessary; however, the use of technologies is the most common strategy and requires a computer and a word processor (e.g., Microsoft ${ }^{\oplus}$ Word). Alternatively, headphones, foot pedals, and an external mouse and keyboard (in the case of laptops) can also be used. In addition, it may be beneficial to use specific software since it offers a set of tools that facilitate and optimize the task. $\mathrm{NCH}^{\odot}$ Express Scribe, for example, has very attractive advantages: it is a free tool, available online, that allows working in a single window and using features such as pausing, rewinding, and slowing down the recording; Prepare the coversheet (McLellan et al. 2003), including basic information on the context of the interview and the interviewee, in order to facilitate the transcriber's first contact with the recording. In addition, the cover sheet can also work as a means of communication between the interviewer and the transcriber (Table 1); Identify the interviewer and the interviewee and select a transcription scheme: given that there are different ways to identify those involved in an interview and their interaction, it is essential to define in advance the schemes to be implemented (Table 1); Define the type of transcription, namely naturalized versus denaturalized, because they will ultimately lead to different products. While some authors believe that most qualitative analyses do not benefit from a transcription that includes pauses, false starts, repeated sentences, interruptions, or encouragement, and advocate their exclusion (Sandelowski, 1994) in order to ensure that the transcription process focuses on the accuracy of the information content (Stuckey, 2014), other authors recommend the inclusion of contextual and non-verbal information, because they believe that what is not said is as relevant as what is actually said (Bazeley, 2013; Richards, 2014). In line with McLellan et al. (2003), we believe that the content to be included should derive from the research question and the method of data analysis, which should guide the definition of the relevant aspects for the transcription (Table 1). 
Table 1

Some practical guidelines and examples

\begin{tabular}{llll}
\hline Steps & Practical Guidelines & Options & Examples \\
\hline Material identification & $\begin{array}{l}\text { Assigning a code to each } \\
\text { interview }\end{array}$ & Int10; NUR3_M._Jan03 \\
\hline & $\begin{array}{l}\text { Divided into three parts: } \\
\text { identification }{ }^{1} \text {, contextual } \\
\text { information }{ }^{1} \text {, additional } \\
\text { information }\end{array}$
\end{tabular}

\begin{tabular}{|c|c|c|c|}
\hline \multirow[b]{2}{*}{ Transition scheme } & \multirow{2}{*}{$\begin{array}{l}\text { Linear } \\
\text { Tabular }\end{array}$} & \multicolumn{2}{|c|}{$\begin{array}{l}\text { I: What is your opinion about nursing training on } \\
\text { intervention in obesity? } \\
\text { Nur3: It is an area where, unfortunately, there is not so } \\
\text { much training as there should be. }\end{array}$} \\
\hline & & $\begin{array}{l}\text { I: What is your opinion } \\
\text { about nursing training } \\
\text { on intervention in } \\
\text { obesity? }\end{array}$ & $\begin{array}{l}\text { Nur: It is an area where, } \\
\text { unfortunately, there is not } \\
\text { so much training as there } \\
\text { should be. }\end{array}$ \\
\hline
\end{tabular}

Sequential

II: What is your opinion about nursing training on intervention in obesity? Nur: It is an area where, unfortunate, there is not so much training as there should be.

But in terms of motivation, really, and openness to change habits and do something that requires sacrifices (interruption - phone rings but the call is ignored) I'm Naturalized sorry. Hum... Overall, they are not very motivated to do this (pause). They want (laughs gently) a miraculous solution which is normally what they are looking for here!

Type of transcription (gently laughs)

But in terms of motivation, really, and openness to change habits and do something that requires sacrifices...I'm sorry.

Denaturalized Hum... Overall, they are not very motivated to do this. They want a miraculous solution which is normally what they are looking for here!

$\begin{array}{ll}\text { Confidentiality and } & \begin{array}{l}\text { Omitting or removing data/ } \\ \text { information, replacing them } \\ \text { with codes, changing words, } \\ \text { or eliminating them }\end{array} \\ & \begin{array}{l}\text { Times New Roman or Arial; } \\ \text { double spacing; margins } \\ \text { of } 1.5 \text { inches; no indents; } \\ \text { interviewer's interventions } \\ \text { in bold }\end{array} \\ \begin{array}{l}\text { Header: identification of the } \\ \text { interview, the interviewer, } \\ \text { and the transcriber }\end{array} \\ \begin{array}{l}\text { Footnote: page numbers } \\ \text { Indicate the beginning and } \\ \text { the end of interview }\end{array}\end{array}$

F. thinks that I don't know about the disease;

Ana thinks that I don't know about the disease; (removal of sensitive content) thinks that I don't know about the disease.

\section{I: How do you feel in those circumstances?}

PNur10: What do you mean? I don't understand?

I: When, despite your recommendations, the patients return to the consultation with the same weight?

PNur10: I feel frustrated! I feel really frustrated!

INT0402 I1 T2

BEGINNING OF THE INTERVIEW - END OF THE INTERVIEW 


\section{Step 2. Know}

After the preparatory phase and before moving on to writing, some time should be invested in getting to know and becoming familiarized with some materials and information, using the: Organization of the interviewer's field notes, which should be read and analyzed in detail, because they can contain clues and useful information at the time of transcribing; Repeated listening (at least twice) of the recording in full (e.g., Bailey, 2008). This will facilitate becoming familiar not only with the content but also with the speech peculiarities of those involved; Recording of information or data that may be useful when you start writing, such as names or specific terminology.

Step 3: Write

This phase is the act of transcribing itself. With a view to maximizing the writing process, the purpose is simply to listen and write; therefore, at this stage, it is advisable to: Ignore the punctuation, uppercase or lowercase letters, non-verbal interactions between the interviewer and the interviewee, as well as emotional aspects (if they are to be preserved); Use the codebook whenever necessary. A codebook is an essential tool in the transcription process (e.g., Bailey, 2008; Davidson, 2009; Oliver et al., 2005) because it allows standardizing procedures and forms of writing what is less objective; for example, how to approach a silence or cross talk. It should be noted that, although the codebook is defined at an early stage of the process, it can be updated whenever necessary. To illustrate this, since there are no universal codebooks (McLellan et al., 2003), some of the codes used are shown in Table 2; Dealing with confidentiality and sensitive issues: the interviews often contain information that may allow identifying those involved or specific situations. In these cases, it is important to implement strategies to maintain the relevant content while safeguarding the non-recognition of persons or situations (Table 1); Avoid deadends: when difficulties arise in understanding the recording, you may define the maximum number of times to repeat the excerpt (e.g., only three times) and, if this effort is unsuccessful, you should highlight that segment in the text, and then ask the interviewer about the content (the shorter the time interval between the interview and its transcription, the easier it will be for the interviewer to remember the interview).

Finally, it is important to underline that the content and/or the intent of what is said should not be changed (e.g., adding words to the speech).

Table 2

Codebook: Examples of Codes Used in Transcriptions

\begin{tabular}{lll}
\hline When in the recording... & In the transcription... & Example \\
\hline You cannot hear what the person is saying & Information inside parentheses & (inaudible text segment) \\
\hline $\begin{array}{l}\text { You cannot understand what the person } \\
\text { is saying }\end{array}$ & Information inside parentheses & $\begin{array}{l}\text { Yes, exactly! Of course (unintelligible } \\
\text { segment) are a third! }\end{array}$ \\
$\begin{array}{l}\text { You are unsure about what the person is } \\
\text { saying }\end{array}$ & $\begin{array}{l}\text { Inside parenthesis and delimited by } \\
\text { question marks }\end{array}$ & $\begin{array}{l}\text { It's not just a matter of facilitation, } \\
\text { isn't it? And of ?(capacity)? but lack of } \\
\text { knowledge! }\end{array}$ \\
$\begin{array}{l}\text { You cannot understand because of cross- } \\
\text { talk }\end{array}$ & $\begin{array}{l}\text { That piece of information inside } \\
\text { parentheses }\end{array}$ & $\begin{array}{l}\text { (unintelligible segment due to } \\
\text { overlapping speech/cross-talk) }\end{array}$ \\
$\begin{array}{l}\text { A cross-talk begins } \\
\text { A cross-talk ends }\end{array}$ & $\begin{array}{l}\text { Open square bracket } \\
\text { If you believe that the interviewee } \\
\text { mispronounced the word }\end{array}$ & $\begin{array}{l}\text { Closed square bracket } \\
\text { The exact transcription of what was } \\
\text { delimited by slashes }\end{array}$ \\
\hline
\end{tabular}




\begin{tabular}{lll}
\hline Interruption/word is cut & Hyphen at the end & Respond- \\
\hline To include notes/explain interruptions & Text in italic inside parentheses & $($ xxxxxx) \\
\hline Non-verbal sounds (e.g., emotions) & Information inside parenthesis & (laughed); (sighed) \\
\hline Silence/pauses & Three ellipses inside parentheses & $(\ldots)$ \\
\hline The person emphasizes the speech & Underlined & $\begin{array}{l}\text { But it indeed ends up being an } \\
\text { epidemics (strong intonation) both } \\
\text { nationally and internationally. }\end{array}$ \\
\hline Interjections & The following designations: & $\begin{array}{l}\text { Hmm } \\
\text { Mm }\end{array}$ \\
& & Ah \\
\hline
\end{tabular}

\section{Step 4. Edit}

At this stage, the attention goes to the editing of the text resulting from the previous step, which implies: Including punctuation, which represents an exceptional challenge, since it involves identifying where it is necessary, in order not to change the purpose or unduly emphasize an answer, or part thereof (McLellan et al., 2003); Distinguishing between uppercase and lowercase letters; Retaining emotional and non-verbal aspects (where applicable): once again, this task should be carefully done, since representation may change the interpretation of a text segment (Stuckey, 2014); Dealing with errors of oral speech: oral speech is susceptible to the occurrence of grammatical, syntactic, and prosodic errors, and, as such, the transcriber is often confronted with too flagrant mistakes (which can even create some discomfort or become distracting). There are essentially two options to deal with oral mistakes: Ignoring or correcting, and this decision can (and should) be made explicit on the coversheet. Although it may seem a detail, in fact, in certain contexts and with certain objectives, the suitability and correction of the oral speech can be a relevant variable, while in other cases it may not have any interest. Regardless of the strategy, it is important to safeguard the equal treatment of those involved, correcting or maintaining the interventions of both interviewer and interviewee (Oliver et al., 2005); Formatting the document in accordance with the previously established rules (Table 1).

Step 5. Review

In this step, the text resulting from the transcription is compared to the recording so as to check the accuracy of the transcribed information. Thus, to ensure a good review, it is important: To involve other people, in addition to the transcriber, in the task - ideally the interviewer or, when it is not possible, another person who is highly familiarized not only with the transcription protocol but also with the topic (McLellan et al., 2003); To compare the transcript with the field notes to identify points of disagreement.

\section{Step 6. Finish}

After reviewing the transcript, it is important to pay attention to two issues, namely: What to do with the recordings? Data often refer to people and their life histories, behaviors, opinions, emotions, and so forth, which is potentially sensitive information that must be safeguarded and that may be particularly threatened by the existence of audio recordings. Therefore, the ideal solution is to erase or destroy the recordings. In some situations, they must be kept for a specific timeframe in a safe place with restricted access until they are destroyed (McLellan et al., 2003); Is it better to have one or two transcript versions? As previously mentioned, transcripts may vary depending on the amount and quality of the information retained. In some cases, as suggested by Oliver et al. (2005), two versions can be made: a full version (which may include verbal and non-verbal content and occurrences along the interview) and a working version (in which information deemed irrelevant to the goals is omitted). The creation of both versions takes more time and extra work; however, if the recordings are no longer available, it will allow going back and see the full version, whenever necessary and/or relevant. 


\section{Challenges}

In view of the previous guidelines, transcribing is not necessarily a task that requires a high degree of specialization, but this does not mean that it is an easy task. Quite the opposite, it usually involves significant time, physical, and human resources (Halcomb \& Davidson, 2006). Recognizing that every transcription experience has its special characteristics and, as a result, leads to specific difficulties, there are several recurring challenges and obstacles that can be anticipated, analyzed, and addressed, thus preventing them from delaying or blocking task performance.

One of the main challenges is the quality and volume of the recording itself, as well as contextual aspects, such as background noise, interference or other sounds (e.g., a door that opens; Bailey, 2008). In relation to those involved, it is important to point out the speech characteristics such as different pronunciations, regionalism, or constant pausing. In addition to these, cross talk or overlapping speech, incomplete sentences, omission or addition of letters in words, and the lack of clear-cut endings of ideas are also difficulties experienced while transcribing an interview (McLellan et al., 2003).

The biggest challenge of transcription relates to the amount of time involved, which, although it is quite variable, is always disproportional to the duration of the recording. For example, according to Bailey (2008), 1 hour of recording can take up to 3 hours to be transcribed if you only write what is said, or 10 hours if you register in detail what is said, how it is said and in what context. The variables prior experience and training significantly influence the relationship between the duration of the interview and the time required to transcribe it. Despite this, it is undeniable that the high amount of time required contributes to its perception not only as a boring but also as a physically exhausting activity (e.g., several hours in the same position, high levels of concentration and attention). Faced with this reality, it is important to pay special attention to the location and the conditions in which the task is performed, ensuring basic aspects such as comfort, brightness, or regular breaks.

\section{Conclusion}

After revisiting the main conceptual issues, practical guidelines, and challenges inherent to interview transcription, it is evident that this process involves many different (often implicit) decisions, which were explained in the previous sections. To sum up, more relevant than presenting the product is to make some comments about the process.

First, it is important to recognize that there are no universal rules or protocols to perform transcriptions. Quite the opposite, transcribing is a quite eclectic task, which requires those involved to understand, establish, and assume a set of principles and practices, in an attempt to harmonize transcripts and, consequently, avoid wasting time and work and interpersonal conflicts. Finally, it is important to identify the implications and recommendations for theory, practice, and research. Although transcribing may seem a minor task of transition between primary steps, the truth is that transcriptions are powerful (both upstream and downstream). In this sense, the topic should be valued both from a theoretical perspective (i.e., a higher number of publications; more specialized focus) and a practical perspective (i.e., clear description of the procedures and decisions and their potential repercussions). In addition, it is important to recognize the obvious impact on research, since the quality of data analysis is intimately related to the quality of transcription.

In summary, due to the absence of universal rules or protocols to transcribe, allied to the interpretative and transformative features of the task, it is crucial that researchers present their practices and decisions in a clear manner.

This study was conducted at Psychology Research Centre (UID/PSI/01662/2013), University of Minho, and supported by the Portuguese Foundation for Science and Technology and the Portuguese Ministry of Science, Technology and Higher Education through national funds and co-financed by FEDER through COMPETE2020 under the PT2020 Partnership Agreement (POCI-010145-FEDER-007653) 


\section{References}

Bailey, J. (2008). First steps in qualitative data analysis: Transcribing. Family Practice, 25(2), 127-131. doi:10.1093/fampra/cmn003

Bazeley, P. (2013). Qualitative data analysis: Practical strategies. London, England: Sage Publications.

Bucholtz, M. (2000). The politics of transcription. Journal of Pragmatics, 32(10), 1439-1465. doi:10.1016/ S0378-2166(99)00094-6

Camarneiro, A. P., Maciel, J. C., \& Silveira, R. M. (2015). Vivências da interrupção espontânea da gravidez em primigestas no primeiro trimestre gestacional: Um estudo fenomenológico. Revista de Enfermagem Referência, 4(5), 109-117. doi: 10.12707/RIV14064

Creswell, J. (2013). Qualitative inquiry \& research design: Choosing among five approaches (3rd ed.). Thousand Oaks, USA: Sage Publications.

Davidson, C. (2009). Transcription: Imperatives for qualitative research. International Journal of Qualitative Methods, 8(2), 36-52. doi: http://dx.doi.org /10.1177\%2F160940690900800206

Halcomb, E. J., \& Davidson, P. M. (2006). Is verbatim transcription of interview data always necessary? Applied Nursing Research, 19(1), 38-42. doi: 10.1016/j.apnr.2005.06.001

Lapadat, J. C. (2000). Problematizing transcription: Purpose, paradigm and quality. International Journal of Social Research Methodology, 3(3), 203-219. doi:10.1080/13645570050083698

McLellan, E., MacQueen, K. M., \& Neidig, J. L. (2003). Beyond the qualitative interview: Data preparation and transcription. Field Methods, 15(1), 63-84. doi:10.1177/1525822X02239573

Mergenthaler, E., \& Stinson, C. (1992). Psychothera- py transcription standards. Psychotherapy Research, 2(2), 125-142. doi:10.1080/1050330921233133 2904

Naz. (n.d.). Interview transcribing. Retrieved from http://studylib.net/doc/5568715/transcribing-presentation---wea-west-midlands-region

Oliver, D. G., Serovich, J. M., \& Mason, T. L. (2005). Constraints and opportunities with interview transcription: Towards reflection in qualitative research. Social Forces, 84(2), 1273-1289. doi:10.1353/ sof.2006.0023

Richards, L. (2014). Handling qualitative data: A practical guide. London, England: Sage Publications.

Ritchie, J., Lewis, J., Nicholls, C. M., \& Ormston, R. (2014). Qualitative research practice: A guide for social science students and researchers. London, England: Sage Publications.

Sandelowski, M. (1994). Focus on qualitative methods: Notes on transcription. Research in Nursing \& Health, 17(4), 311-314. doi: 10.1002/ nur.4770170410

Schegloff, E. A. (1997). Whose text?: Whose context? Discourse \& Society, 8(2), 165-187. doi: $10.1177 / 0957926597008002002$

Silverman, D. (2013). Doing qualitative research: A practical handbook. London, England: Sage Publications.

Stuckey, H. L. (2014). The first step in data analysis: Transcribing and managing qualitative research data. Journal of Social Health and Diabetes, 2(1), 6-6. doi:10.4103/2321-0656.120254

Tashakkori A., \& Teddlie C. (2003). Handbook of mixed methods in social and behavioural research. Thousand Oaks, CA: Sage Publications.

Taylor, B., \& Francis, K. (2013). Qualitative research in the health sciences: Methodologies, methods and processes. London, England: Routledge. 
